\title{
Isolasi dan Karakterisasi Senyawa Non Fenolik dari Daun Gowok (Syzygium polycephalum Miq.)
}

\author{
Nur Amalia Choironi ${ }^{1}$, Kaefiyah Nurul Insani ${ }^{1}$, Dina Parika ${ }^{1}$, Sunarto ${ }^{1}$, Ade Martinus ${ }^{2}$, dan \\ Muhamad Salman Fareza'
}

\author{
1 Jurusan Farmasi, Universitas Jenderal Soedirman, Purwokerto \\ 2 Jurusan Kimia, Universitas Jenderal Soedirman, Purwokerto \\ Korespondensi: Muhamad Salman Fareza \\ Email: muhamad.fareza@unsoed.ac.id
}

Submitted: 30-11-2018, Revised: 18-01-2019, Accepted: 03-03-2019

\begin{abstract}
ABSTRAK: Syzygium polychepalum (gowok) merupakan salah satu tanaman yang sering digunakan sebagai obat tradisional di Indonesia. Penelitian ini bertujuan untuk melakukan kajian fitokimia terhadap daun gowok yang berasal dari Purwokerto. Ekstraksi dilakukan dengan cara maserasi, sedangkan fraksinasi dan pemurnian dilakukan dengan metode kromatografi vakum cair dan gravitasi. Karakterisasi senyawa hasil isolasi dilakukan dengan menggunakan metode spektroskopi ${ }^{1} \mathrm{H}-\mathrm{NMR}$ dan GC-MS. Hasil karakterisasi menunjukkan bahwa isolat merupakan senyawa asam lemak jenuh yaitu asam heksadekanoat dan 3-etilpropanoat.
\end{abstract}

Kata kunci: Syzygium polycephalum; daun gowok; isolasi; senyawa non fenolik

\begin{abstract}
Syzygium polychepalum (gowok) is one of the plants frequently used as traditional medicine in Indonesia. This study aims to conduct a phytochemical study of gowok leaves from Purwokerto. Extraction was carried out by maceration, while fractionation and purification was carried out by liquid vacuum and gravity chromatography. Characterization of the isolated compounds was carried out using ${ }^{1} \mathrm{H}$-NMR spectroscopy and GC-MS methods. The characterization results showed that isolates were saturated fatty acid compounds namely hexadecanoic acid and 3-ethylpropanoate.
\end{abstract}

Keywords: Syzygium polycephalum; gowok leaves; isolation; non phenolic compound 


\section{Pendahuluan}

Syzygium adalah genus dari family Myrtaceae yang mempunyai jenis terbanyak di Indonesia (lebih dari 300 jenis) dan sekitar 60 jenis berada di Jawa. Beberapa jenis dari genus ini mempunyai nilai ekonomi yang penting baik sebagai penghasil buah, kayu, maupun tanaman obat [1]. Menurut Sunarti [1] terdapat 25 jenis Syzygium yang bermanfaat sebagai sumber bahan obat, salah satunya adalah Syzygium polychepalum (gowok). Tanaman ini secara empiris bermanfaat untuk mengatasi diare, maag, dan gatal pada kulit.

Kajian fitokima terhadap spesies ini diantaranya dilakukan oleh Ragasa et al. [2] yang telah melaporkan bahwa bagian daun S. polychepalum asal Filipina mengandung senyawa triterpen dan steroid yaitu asam ursolat, asam oleanolat, skualen dan $\beta$-sitosterol dengan sifat antikanker. Selain itu, senyawa turunan asam elagat yaitu asam 3,4,3'-tri-0-metilelagat juga telah diisolasi dari kulit batang gowok asal Ngawi, Jawa Timur Indonesia dengan sifat sebagai antioksidan [3]. Penelitian terkait kajian fitokimia dari S. polychepalum yang berasal dari Purwokerto, Jawa tengah hingga saat ini belum ada yang melaporkan. Oleh karena itu, penelitian ini bertujuan untuk mengisolasi dan mengidentifikasi kandungan senyawa dari daun gowok yang berasal dari Purwokerto.

\section{Bahan dan metode}

\subsection{Bahan kimia}

Bahan yang digunakan adalah plat KLT silika gel 60 GF 254 (Merck), silika gel 60 G 107734 (Merck), silika gel 60 G 107731 (Merck), akuades, pelarut-pelarut organik teknis yang telah didestilasi sebelumnya dan pure analysis seperti: etanol $96 \%, n$-heksan, etil asetat, metanol, dan kloroform (Merck).

\subsection{Bahan tanaman}

Daun Syzygium polycephalum diperoleh dari koleksi kebun Botani Fakultas Biologi Universi- tas Jenderal Soedirman pada bulan Febuari 2018. Identifikasi tumbuhan dilakukan di Laboratorium Taksonomi Tumbuhan, Fakultas Biologi Universitas Jenderal Soedirman, dan diidentifikasi sebagai tanaman Syzygium polycephalum.

\subsection{Pembuatan simplisia}

Sebanyak $3 \mathrm{~kg}$ sampel daun sebelumnya disortasi basah, dicuci untuk menghilangkan debu dan kotoran lalu dirajang, selanjutnya daun dikeringkan. Daun yang sudah kering dihaluskan hingga menjadi serbuk. Kemudian simplisia yang berupa serbuk dikemas dan disimpan di tempat yang udaranya cukup kering [4].

\subsection{Ekstraksi}

Sebanyak 1,5 kg serbuk kering S. polychepalum dimaserasi menggunakan pelarut etanol $96 \%$ selama 24 jam dan diremaserasi sebanyak 2 kali dengan pelarut dan metode yang sama. Filtrat yang didapatkan kemudian dipekatkan dengan menggunakan vacuum rotary evaporator pada temperatur $60^{\circ} \mathrm{C}$ sehingga dihasilkan ekstrak kental [5].

\subsection{Fraksinasi dan pemurnian}

Sebanyak 30,3 g ekstrak etanol S. polychepalum difraksinasi dengan kromatografi vakum cair (KVC). Fase diam yang digunakan yaitu silika gel 60 G 107731. Fase gerak yang digunakan pada proses fraksinasi menggunakan EtOAc : $\mathrm{CHCl}_{3}$ secara gradien dengan perbandingan yang berbeda-beda. Fraksi-fraksi yang telah didapatkan dipisahkan dan dimurnikan dengan kromatografi kolom dengan fase gerak EtOAc : $n$-heksan $(3,5$ : 6,5) dan $n$-heksan : $\mathrm{CHCl}_{3}$ (1:1) hingga didapatkan isolat murni. Isolat yang sudah didapatkan dilakukan uji kemurnian dengan sistem tiga eluen yang berbeda menggunakan KLT. Isolat dikatakan murni apabila menunjukkan satu bercak saat uji kemurnian [6].

\subsection{Identifikasi senyawa}

Identifikasi senyawa dilakukan dengan menggunakan ${ }^{1} \mathrm{H}-\mathrm{NMR}(500 \mathrm{MHz}$ ) (Agilent DD2) de- 
ngan pelarut $\mathrm{CDCl}_{3}$ dan GC-MS (GCMS-QP2010 Ultra). Kondisi GC-MS yang digunakan yaitu dengan menggunakan kolom Rtx-5MS, suhu terprogram, suhu kolom awal $60^{\circ} \mathrm{C}$ dan akhir $270^{\circ} \mathrm{C}$, suhu injektor $280^{\circ} \mathrm{C}$, gas pembawa helium (He) dan detektor FTD.

\section{Hasil dan pembahasan}

\subsection{Maserasi}

Serbuk kering simplisia daun S. polychepalum diekstraksi dengan metode maserasi menggunakan pelarut etanol 96\%. Metode maserasi digunakan karena metode ini sederhana dan tanpa pemanasan sehingga dapat mencegah rusak atau hilangnya zat aktif selama ekstraksi [7]. Pelarut etanol digunakan dalam proses maserasi karena etanol dapat melarutkan senyawa dari yang non polar hingga polar. Etanol juga memiliki titik didih yang rendah, aman, tidak toksik, dan tidak berbahaya [8].

Maserasi dilakukan selama 1 x 24 jam dengan 2 kali pengulangan (remaserasi). Remaserasi bertujuan untuk mendapatkan senyawa yang lebih banyak karena dengan adanya pergantian pelarut dengan pelarut yang baru maka gradien konsentrasi antara pelarut dan sel berbeda jauh, sehingga mempermudah penarikan-penarikan senyawa yang ada dalam sel [9]. Maserat disaring dan dievaporasi menggunakan vacuum rotary evaporator. Hasil maserasi dari 1,5 kg serbuk simplisia diperoleh ekstrak kental yaitu sebesar $92,126 \mathrm{~g}$ dengan rendemen sebesar $6,14 \%$.

\subsection{Fraksinasi dan pemurnian}

Ekstrak sebanyak 30,3 g difraksinasi menggunakan kromatografi vakum cair (KVC). Fase diam berupa silika gel 60 G 107734 . Proses elusi yang dilakukan bersifat gradien yaitu dengan penambahan tingkat kepolaran fase gerak selama kromatografi berlangsung [10]. Fase gerak yang digunakan yaitu campuran EtOAc: $\mathrm{CHCl}_{3}(1: 9)$ sebanyak 3 kali, EtOAc : $\mathrm{CHCl}_{3}$ (3:7) sebanyak 3 kali, EtOAc : $\mathrm{CHCl}_{3}$ (1:1) sebanyak 3 kali, EtOAc 1 kali dan $\mathrm{MeOH} 1$ kali hingga diperoleh 11 fraksi.

Fraksi (3-6) (0,15 g) dilakukan pemisahan dengan kromatografi kolom menggunakan fase gerak EtOAc : $n$-heksan (3,5:6,5). Fraksi (3-6) menghasilkan 5 fraksi utama. Fraksi (3-6).2 (0,13 gram) dipisahkan secara kromatografi kolom menggunakan fase gerak $n$-heksan : $\mathrm{CHCl}_{3}$ (1:1). Fraksi (3-6).2 menghasilkan 3 fraksi utama. Fraksi (3-6).2.2 (18,3 mg) dilakukan uji kemurnian dengan sistem 3 eluen yang berbeda menggunakan $n$-heksan : $\mathrm{CHCl}_{3}$ (3:7), $n$-heksan : EtOAc (10:1), dan $\mathrm{CHCl}_{3}$. Setelah dilakukan uji kemurnian didapatkan bahwa fraksi (3-6).2.2 sebagai isolat sudah murni karena menghasilkan satu bercak saat dianalisis dengan KLT.

\subsection{Identifikasi senyawa}

Hasil spektrum ${ }^{1} \mathrm{H}-\mathrm{NMR}$ isolat memperlihatkan adanya 5 sinyal utama yaitu 0,68 ppm $(1 \mathrm{H}$, s); 0,78-1,03 ppm $(12 \mathrm{H}, m) ; 1,28 \mathrm{ppm}(12 \mathrm{H}, \mathrm{s})$; 1,54 ppm (20H, s); 3,89 ppm (1H, s) (Gambar 1). Berdasarkan hasil ${ }^{1} \mathrm{H}-\mathrm{NMR}$, sinyal utama pada isolat (3-6).2.2 berada pada geseran kimia 0,68 ppm - 3,89 ppm, sehingga kemungkinan adalah senyawa non fenolik. Senyawa non fenolik berada pada geseran kimia 1 - 5 ppm [11]. Sedangkan, senyawa fenolik berada pada geseran kimia 6 - 9 ppm [12]. Senyawa yang termasuk golongan non fenolik adalah steroid, terpenoid dan asam lemak. Spektrum ${ }^{1} \mathrm{H}-\mathrm{NMR}$ pada senyawa terpenoid dan steroid memiliki ciri yaitu senyawa terpenoid memiliki sinyal singlet untuk gugus metil $\left(-\mathrm{CH}_{3}\right)$ pada geseran kimia 0 - 1 ppm, sedangkan senyawa steroid memiliki sinyal singlet untuk gugus metil $\left(-\mathrm{CH}_{3}\right)$ pada geseran kimia $0,6-0,7$ ppm $[13,14]$. Senyawa asam lemak atau ester dari asam-asam lemak memiliki ciri adanya gugus metil $\left(-\mathrm{CH}_{3}\right)$ terminal yang muncul sebagai triplet pada nilai geseran kimia sedikit di bawah 1 ppm (antara 0,8 1,0 ppm) [11,15]. Pada isolat (3-6).2.2 terdapat sinyal multiplet pada geseran kimia 0,78 - 1,03 ppm, hal ini dimungkinkan pada sinyal tersebut terdapat lebih dari satu metil pada lingkungan kimia yang berbeda, salah satunya terdapat gugus metil terminal dengan multiplisitas triplet 


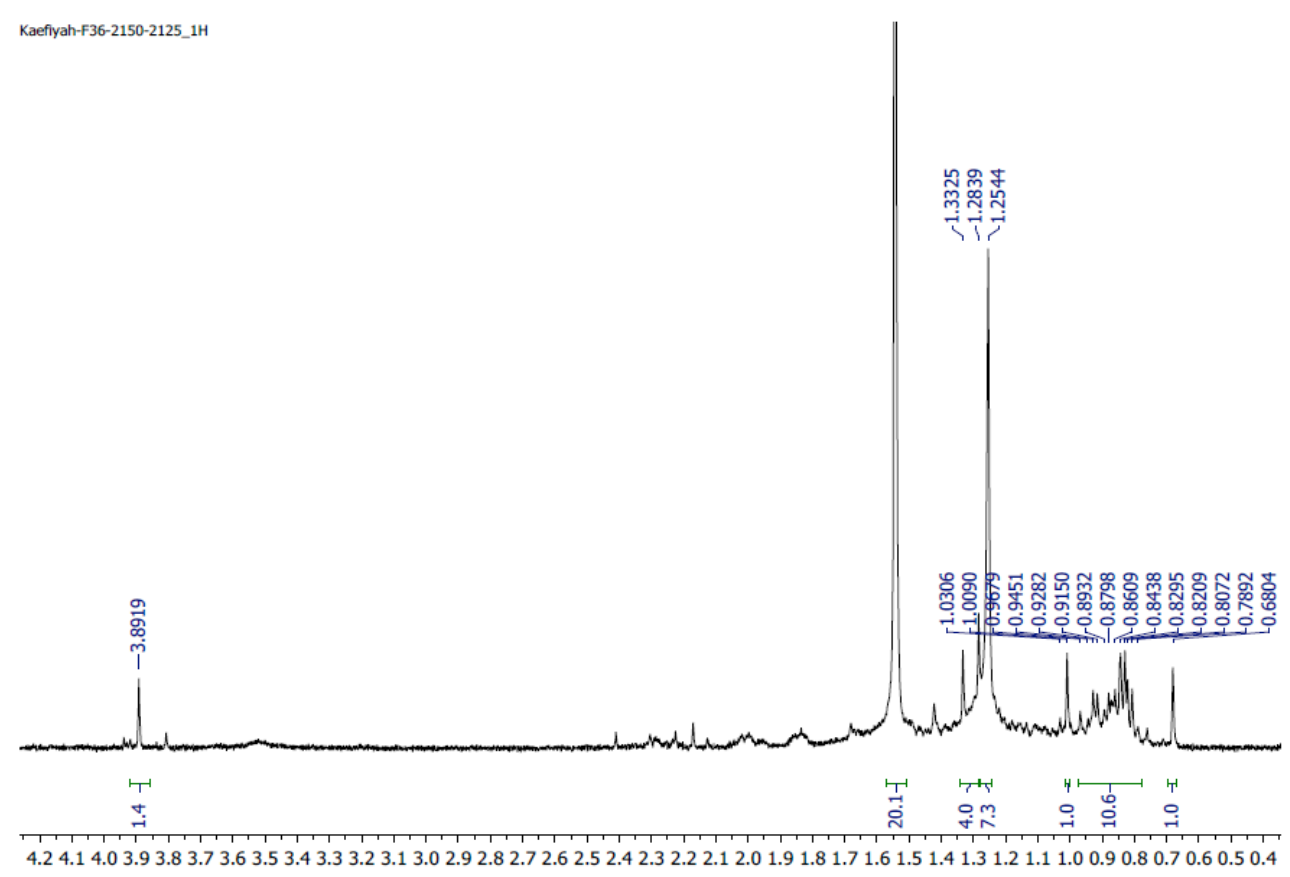

Gambar 1. Spektrum ${ }^{1} \mathrm{H}-\mathrm{NMR}$ isolat (500 MHz, $\mathrm{CDCl}_{3}$ )

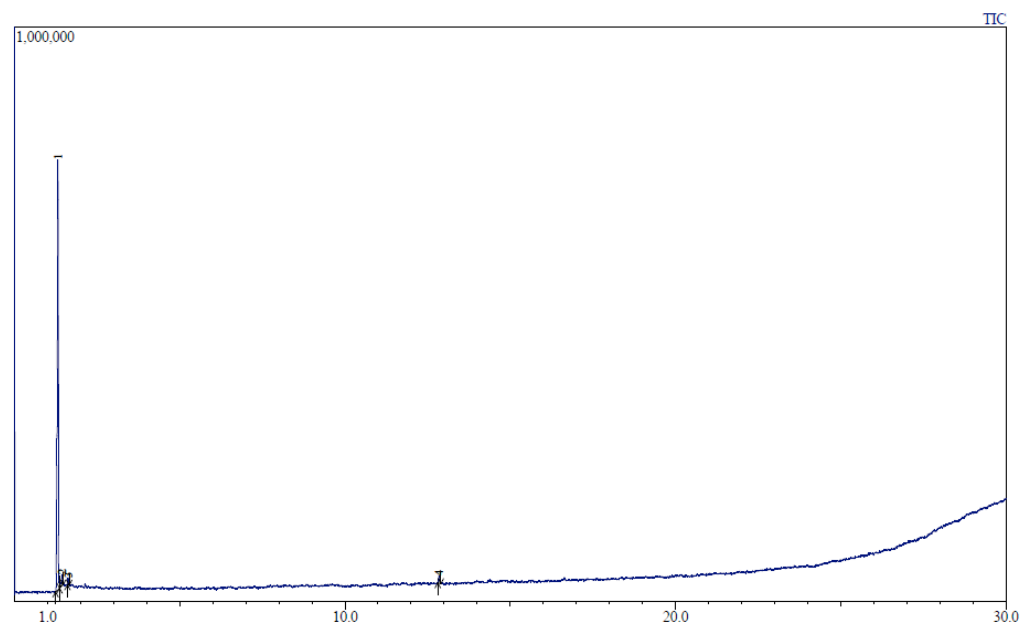

Gambar 2. Kromatogram GC isolat

Tabel 1. Data GC-MS Isolat

\begin{tabular}{cllllll}
\hline Peak & tR & Area & \% Area & Tinggi & A/T & Senyawa \\
\hline 1 & 1,625 & 16827 & 1,06 & 12618 & 1,33 & Metil 3-etilpropanoat \\
2 & 12,852 & 33944 & 2,14 & 13522 & 2,51 & Asam heksadekanoat metil ester \\
\hline
\end{tabular}

yang merupakan ciri dari senyawa asam lemak [15]. Sinyal singlet yang sangat tinggi pada daerah 1,28 ppm dan 1,54 ppm pada isolat (3-6).2.2 mirip dengan sinyal singlet pada senyawa asam lemak yang berada pada geseran kimia 1,3-1,5 ppm untuk gugus metilen $\left(-\mathrm{CH}_{2}\right)[16]$.

Asam lemak terdiri dari asam lemak jenuh dan asam lemak tak jenuh. Senyawa asam lemak tak jenuh memiliki gugus fungsi yang berada pada geseran kimia 2,03 ppm dan 5,3 ppm yang meru- 
pakan sinyal proton alkena. Pada isolat (3-6).2.2 tidak terdapat sinyal pada daerah 2,03 ppm dan 5,3 ppm, sehingga kemungkinan isolat tersebut merupakan asam lemak jenuh karena tidak terdapat gugus alkena [12]. Pada senyawa asam lemak tidak terdapat ciri adanya sinyal singlet pada daerah 3,89 ppm dengan integritas $1 \mathrm{H}$, sehingga dapat dimungkinkan bahwa sinyal yang terdapat pada isolat (3-6).2.2 daerah 3,89 ppm tersebut adalah pengotor [15]. Terdapat dua jenis asam lemak jenuh pada isolat (3-6).2.2, karena terlihat bahwa terdapat dua sinyal singlet yang tinggi pada daerah 1,28 ppm dan 1,54 ppm yang merupakan ciri dari asam lemak [16].

Berdasarkan hasil analisis GC-MS, isolat merupakan campuran dari dua asam lemak jenuh yaitu asam heksadekanoat metil ester pada tR 12,852 menit dan metil 3-etilpropanoat pada tR 1,625 menit (Gambar 2 dan Tabel 1). Pada proses GCMS, sampel yang berupa isolat dilakukan proses esterifikasi. Oleh karena itu, senyawa asam lemak jenuh yang terdapat pada isolat kemungkinan adalah asam heksadekanoat dan 3-etilpropanoat. Pada spektrum ${ }^{1} \mathrm{H}-\mathrm{NMR}$, sinyal singlet yang tinggi pada daerah 1,28 ppm diperkirakan merupakan sinyal milik 3-etilpropanoat dan sinyal singlet yang tinggi pada daerah 1,54 ppm dengan integritas lebih besar merupakan sinyal milik asam heksadekanoat.

Kandungan asam lemak dari S. polychepalum ini baru pertama kali dilaporkan. Beberapa senyawa asam lemak telah dilaporkan pada genus Syzygium diantaranya pada Syzygium zeylanicum, Syzygium aromaticum, dan Syzygium cumini [1719]. Menurut beberapa penelitian, asam lemak dilaporkan memiliki efek farmakologis tertentu seperti antibakteri, antifungi, dan antioksidan [20-21].

\section{Kesimpulan}

Berdasarkan penelitian yang dilakukan, hasil isolasi kandungan kimia dari tanaman gowok (Syzygium polychepalum Miq.) asal Purwokerto merupakan senyawa turunan asam lemak jenuh yaitu asam heksadekanoat dan 3-etilpropanoat.

\section{Ucapan Terimakasih}

Terimakasih kepada Kementrian Riset dan Teknologi Indonesia dan Universitas Jenderal Soedirman atas bantuan dana penelitian melalui skim BLU RISET KOMPETENSI Tahun 2018.

\section{Daftar Pustaka}

1. Sunarti S. Persebaran Syzygium endemik Jawa. Pros Sem Nas Masy Biodiv Indon. 2015;1(5):1093108.

2. Ragasa CY, Torres OB, Shen CC, Lachica MK, Sulit AB, Chua DB, Ancheta AD, Ismail CJ, Bernaldez FT, Raga DD. Triterpenes from the leaves of Syzygium polycephalum, S. cumini, and S. samarangense. Chemistry of Natural Compounds. 2014;50(5):942-4.

3. Tukiran AWN, Hidayati N, Shimizu K. An Ellagic Acid Derivative And Its Antioxidant Activity of Chloroform Extract of Steam Bark of Syzygium polychepalum Miq. (Myrtaceae). Indon. J. Chem. 2018;18(1):26-34.

4. Depkes RI. Sediaan Galenika. Jakarta: Departemen Kesehatan Republik Indonesia; 1986.

5. Syamsuni HA. Ilmu Resep. Jakarta: EGC; 2006.

6. Atun S. Metode Isolasi dan Identifikasi Struktur Senyawa Organik Bahan Alam. Jurnal Konservasi Cagar Budaya Borobudur. 2014;8(2):53-61.

7. Sa'adah H, Nurhasnawati H. Perbandingan Pelarut Etanol dan Air pada Pembuatan Ekstrak Umbi Bawang Tiwai (Eleutherine americana Merr.) Menggunakan Metode Maserasi. Jurnal Ilmiah Manuntung. 2015;1(2):149-53.

8. Azis T, Febrizky S, Mario AD. Pengaruh Jenis Pelarut Terhadap Persen Yield alkaloid dari Daun Salam India (Murraya koenigii). Jurnal Teknik Kimia. 2014;20(2):1-6.

9. Pratiwi. Perbandingan Metode Maserasi, Remaserasi, Perkolasi dan Reperkolasi Dalam Ekstraksi Senyawa Aktif Andrographolide dari Tanaman 
Sambiloto (Andrographis paniculata (Burm.F.) Nees). Bogor: Fakultas Teknologi Pertanian Institut Pertanian Bogor, Skripsi; 2010.

10. Shrivastava A, Gupta VB. HPLC: Isolation or Gradient Elution and Assesment of Linearity In Analytical Methods. Journal of Advanced Scientific Research. 2012;3(2):12-20.

11. Syah YM. Dasar-Dasar Penentuan Struktur Molekul Berdasarkan Data Spektrum ${ }^{1} \mathrm{H} \&{ }^{13} \mathrm{C}$-NMR. Bandung: Institut Teknologi Bandung; 2016.

12. Gogna N, Hamid, N, Dorai K. Metabolomic Profiling of The Phytomedicinal Constituents of Carica papaya L. Leaves and Seeds by ${ }^{1} \mathrm{H}$-NMRS spectroscopy and Multivariate Statistical Analysis. Journal of Pharmaceutical and Biomedical Analysis. 2015;115:74-85.

13. Yoosuf-Aly Z, Faraldos JA, Miller DJ, Allemann RK. Chemoenzymatic synthesis of the alarm pheromone (+)-verbenone from geranyl diphosphate. Chemical Communications. 2012;48(56):7040-2.

14. Mannina L, Segre A. High Resolution Nuclear Magnetic Resonance: From Chemical Structure to Food Authenticity. Grasas y Aceitis. 2002;53(1):22-33.

15. Gustone FD, Harwood JL, Padley FB. The Lipid Handbook 2nd edition. London; 1995.
16. Knothe G. ${ }^{1}$ H-NMR Spectroscopy of Fatty Acids and Their Derivatives, http://lipidlibrary.aocs. org/, diakses pada Juni 2018.

17. Bhanu DRC, Sabu KK. Fatty Acid Composition of The Fruits of Syzygium zeylanicum (L.) Dc. var. zeylanicum. International Journal of Current Pharmaceutical Research. 2017;9(5):155-7.

18. Gupta M, Singh D, Gularia P, Gupta S. GCMS Analysis and Identifications of Chemical Constituents of Syzygium aromaticum, Brassica compestris and cow ghee. Journal of Chemical and Pharmaceutical Research. 2015;7(1):568-72.

19. Proma NM, Naima J, Islam MR, Papel JA, Rahman MM, Hossain, MK. Phytochemical Constituents and Antidiabetic Properties of Syzygium Cumini Linn. Seed. International Journal of Pharmaceutical Sciences and Research. 2018;9(8):1806-14.

20. Murhadi M. Senyawa dan Aktivitas Antimikroba Golongan Asam Lemak dan Esternya dari Tanaman. Jurnal Teknologi dan Industri Hasil Pertanian. 2012;14(1):97-105.

21. Gunawan IWG, Karda IM. Identifikasi Senyawa Minyak Atsiri dan Uji Aktivitas Antioksidan Ekstrak Etanol Kulit Batang Kepuh (Sterculia foetida L.). Chem. Prog. 2015;8(1):14-9. 